\title{
El terremoto de Tocopilla, Chile: carta abierta a La Presidenta de la República Dra. Michelle Bachelet
}

Miguel Lawner Steiman

\section{Indice}

El terremoto y los días siguientes

Las Sociedades Mixtas del Serviu con los Municipios

Una proposición

Anexo 1.- Funcionamiento de las Sociedades Mixtas durantes los Gobiernos de Salvador Allende y Frei Montalva

Anexo 2.- Algunas de las réplicas a la carta del Arqto. Lawner.

Anexo 3.- Tres imágenes para la historia de Tocopilla.

\section{Resumen:}

El arquitecto Miguel Lawner, ex presidente de VICORMU y de CORMUVAL (19701973), expone en carta abierta a la Presidenta de la República de Chile, Dra. Michelle Bachelet, una proposición para la efectiva reconstrucción de Tocopilla con visión de futuro y sin pérdida de recursos.

Palabras Claves: TOCOPILLA. HUARA. VICORMU. CORMU. CORMUVAL. SOCIEDADES MIXTAS DEL SERVIU - MUNICIPIOS. URCOREI. IQUICORMU. ARQUITECTO MIGUEL LAWNER. ARQUITECTO KARL BRUNNER.

\section{[EI terremoto y los días siguientes]}

Estimada Michelle:

Al día siguiente del terremoto usted llegó a Tocopilla. Recorrió el lugar mientras la tierra se seguía zangoloteando, y pudo constatar personalmente la magnitud de la catástrofe. Su presencia abrió una luz de esperanza para los damnificados, muchos de los cuales quedaron literalmente en la calle, y les aseguró que el gobierno no los dejaría abandonados.

Por televisión la escuché ofrecer subsidios habitacionales a cada una de las familias afectadas, fórmula de dudosa eficacia dado los magros resultados de situaciones anteriores desalentadoras. Ratifiqué ese juicio poco después, al oír la opinión breve y precisa de Luis Moyano, alcalde de Tocopilla: "no quiero un segundo Huara".

Efectivamente, han pasado más de dos años desde el terremoto que asoló Huara y otras aldeas del interior en junio de 2005, y la mayoría de las familias damnificadas continúan alojadas en mediaguas, o en precarios reparos junto a los restos de sus viviendas.

Semejante cuadro afecta a los damnificados de la tragedia en calle Serrano, de Valparaíso, ocurrida en marzo de este año, los que deambulan con los cartones otorgándoles un subsidio entre 320 y 370 UF, sin que encuentren en el mercado una alternativa satisfactoria.

Tocopilla es una localidad de 24.000 habitantes y los daños del terremoto son cuantiosos. Unas 2.500 viviendas están por el suelo, y otras 4.000 presentan daños severos. Algunos servicios como el hospital, la comisaría y el cuerpo de 
bomberos están irrecuperables, así como gran parte del comercio. Muchos establecimientos educacionales quedaron al borde del colapso, por lo cual fue necesario ordenar el fin del año escolar, y las carreteras de acceso a la ciudad están cortadas como consecuencia de los derrumbes.

El gobierno parece haber asumido satisfactoriamente la emergencia. Se movilizó oportunamente para cubrir las necesidades básicas de la población, en especial la reposición de los servicios de luz y agua. Se planificó la distribución de canastas alimenticias en conjunto con la organización vecinal; se avanza en la recolección de los escombros; se instaló un hospital de campaña, se ha vacunado masivamente a la población, y se acelera la construcción de cuatro campamentos con mediaguas, mediante la ayuda del ejército, los voluntarios de "Un techo para Chile" y otras organizaciones sociales.

La designación de una Ministra en Campaña, es otra acción de indudable apoyo a la coordinación de las tareas mas urgentes.

Todo esto indica que la emergencia ha sido eficiente y oportuna. Ahora comienza la etapa mas difícil: la reconstrucción.

Históricamente, el país aprovechó las catástrofes para lograr un auténtico mejoramiento de las zonas afectadas. El terremoto del 39 dio vida a la Corporación de Reconstrucción y Auxilio, organismo dependiente de la CORFO, que le cambió la cara a ciudades como Concepción y Chillán.

Valdivia debe agradecerle al cataclismo de 1960 que haya recuperado la accesibilidad al río, y remozando su desarrollo urbano hasta adquirir el encanto que hoy exhibe.

Esto fue posible ayer, en virtud del activo rol jugado por el sector público, que permitió planificar y coordinar la reconstrucción, tanto del parque habitacional afectado, como también de las obras de infraestructura y de equipamiento urbano. Catástrofes como un terremoto, facilitan la ejecución de muchas obras postergadas por falta de recursos, por disposiciones burocráticas, o por simple desidia. El terremoto despeja los obstáculos que impiden cumplir con múltiples demandas. Es una oportunidad excepcional, que permite convertir la tragedia en un beneficio colectivo.

A raíz del desmantelamiento del aparato estatal efectuado por la dictadura, situación que aun subsiste, el sector público carece de una institucionalidad capaz de asumir una auténtica reconstrucción. Tampoco los municipios cuentan con departamentos aptos para encarar semejante desafío. Los últimos cataclismos han puesto al descubierto este vacío. Se cubre satisfactoriamente la emergencia, pero no la reconstrucción.

Como no hay una cabeza coordinadora de la reconstrucción, cada Ministerio o repartición obra por su cuenta, al margen de un plan coordinado, y se reponen en el mismo sitio las obras siniestradas, cuando podría ocurrir - por ejemplo-que su ubicación sea inadecuada. En materia de vivienda, la acción se reduce a la fórmula ya conocida de otorgar un subsidio a cada familia damnificada, las cuales inician entonces, el calvario de buscar en el mercado algún sustituto al bien raíz perdido, y si encuentran algo, estará alejado de sus localizaciones primitivas, o será de un precario nivel de calidad.

Esta política del subsidio fomenta el individualismo, desaprovechando el potencial que representa la acción colectiva de la comunidad. En una localidad como Tocopilla 
- María Elena, con escasa existencia profesional calificada, los pobladores quedan expuestos a ser engañados por cualquier maestro inescrupuloso o incompetente.

La aspiración abrumadoramente mayoritaria de los afectados es reconstruir las viviendas en su propio sitio, anhelo legítimo, ya que se trata del lugar donde provienen sus raíces, y donde tejieron las redes de amistad, de trabajo, de educación o de abastecimiento a lo largo de los años. Por otra parte, al construir en su propio sitio, se facilita el aprovechamiento de los elementos salvados de la catástrofe: algún tabique intacto, diversas piezas de madera, puertas y ventanas, revestimientos o planchas de techumbre, que se integran a un nuevo proyecto, con evidente disminución de los costos.

Esto es especialmente importante en las zonas históricas, las de mayor valor patrimonial, que son las mas afectadas justamente por su antigüedad. Pero las políticas actuales no incentivan la reconstrucción en el mismo sitio. De hecho la hacen imposible, ya que el monto del subsidio resulta normalmente exiguo para la realización de proyectos no estandarizados.

Finalmente, si algún contratista importante opta por instalarse en la zona, su oferta será localizada en áreas nuevas, donde pueda aplicar economía de escala, proponiendo una solución habitacional tipo, mínima, que calce con los montos del subsidio otorgado.

En resumen, se abandonan los núcleos históricos patrimoniales que quedan degradados, semi en ruinas, y se levanta en las afueras una nueva ciudad, anónima, repetitiva, desprovista de los equipamientos básicos. Concientemente, damos vida a un gheto, mientras tugurizamos la ciudad patrimonial, aquella cuyas calles y muros tienen el encanto insustituible que sólo otorga el pasado.

\section{Las Sociedades Mixtas del SERVIU con los Municipios}

Para abordar una reconstrucción que haga posible el mejoramiento y no el deterioro de las zonas afectadas, se necesita una agencia ejecutiva encargada de planificar el desarrollo urbano, proponiendo los planos seccionales necesarios, con la mas amplia participación de la comunidad y de las autoridades locales.

Esta agencia debe contar con atribuciones para coordinar los proyectos del conjunto de los servicios públicos involucrados, y de visar las inversiones privadas respectivas. Finalmente, debe tener la capacidad de fiscalizar rigurosamente la correcta ejecución de los proyectos.

Organismos de este tipo funcionaron exitosamente en la institucionalidad anterior a la dictadura. Me refiero a las sociedades mixtas establecidas entre la CORMU (Corporación de Mejoramiento Urbano), y algunos municipios.

Durante la administración del presidente Frei Montalva, se creó la VICORMU, sociedad mixta formada por CORMU y la Municipalidad de Viña del Mar. En Valparaíso nació otra similar con el nombre de CORMUVAL.

En el gobierno de Allende las sociedades mixtas de CORMU con otros municipios se extendieron a lo largo de muchas localidades, todas ellas con resultados bastante exitosos en materias del desarrollo urbano, como se detalla en el Anexo a esta carta.

Cuando se creó la CORMU en 1965, su Ley Orgánica la facultó para “colaborar y asociarse con las municipalidades y con las empresas privadas en la realización de proyectos de desarrollo y mejoramiento urbano; otorgar créditos para este fin, supervigilar y fiscalizar su realización y fijar, dentro de las áreas urbanas, los 
límites de las zonas de mejoramiento urbano y procurar su ordenamiento y desarrollo"1.

Al crearse los SERVIU, éstos asumieron las responsabilidades que descansaban anteriormente en la CORVI, COU, CORHABIT y CORMU, es decir, las cuatro corporaciones integrantes del MINVU. Pero también los SERVIU heredaron todas las atribuciones de dichas Corporaciones. En consecuencia, está vigente la facultad legal que los faculta para constituir Sociedades Mixtas ${ }^{2}$ con los Municipios, para poder cumplir con los objetivos señalados mas arriba.

\section{[Una proposición]}

Estimada Michelle:

Propongo la creación de una Sociedad Mixta formada por el SERVIU de la Región de Antofagasta y la Municipalidad de Tocopilla, -llamémosla SERVIUTOC,- a fin de que asuma a la brevedad, la tarea de reconstruir la ciudad. Otra Sociedad análoga debiera crearse con la Municipalidad de María Elena.

Todo el dinero previsto por el MINVU para el otorgamiento de los subsidios familiares a las familias damnificadas por el presente sismo, debiera ser administrado por las sociedades mixtas propuestas para Tocopilla y María Elena, que deberán establecer sus oficinas en el terreno, comenzando con un cuerpo administrativo relativamente pequeño, encabezado por un Gerente Ejecutivo, y por un equipo de profesionales -también instalados en la zona- proveniente de los jóvenes inscritos en el "Programa País", o por quienes respondan a una convocatoria a participar en esta noble misión.

Se sumaría a este equipo directivo, un gran número de jóvenes egresados o cursando el último curso de las carreras de arquitectura, construcción civil, ingeniería, psicología, y periodismo de las Universidades del Norte, a quienes se invitaría a hacer efectiva su práctica profesional en las zonas damnificadas, al menos, entre enero y marzo del próximo año.

Este equipo de profesionales debe asumir la responsabilidad de definir las líneas generales que ordenarán el desarrollo urbano de las áreas siniestradas: asegurar el óptimo uso del suelo; aprovechar de definir posible apertura de nuevas calles o pasajes; ratificar la localización de los equipamientos comerciales, de salud, educación y esparcimiento, o modificarla si es más conveniente.

Además, con el apoyo de los jóvenes estudiantes, la SERVIUTOC debe encargarse de la ejecución y fiscalización de los proyectos individuales o colectivos de vivienda, en conformidad con el deseo de los damnificados, ya sea de permanecer en su sitio, o de mudarse a otra ubicación.

Esta agencia también tendrá a su cargo la contratación de las obras, facilitando la concurrencia de pequeños contratistas o de maestros calificados, para lo cual es necesario eliminar los requerimientos que hacen imposible la adjudicación de obras a este tipo de pequeños contratista, como por ejemplo, la exigencia de boletas de garantía.

Se trata de crear conciencia colectiva de los valores solidarios que inspiran a la reconstrucción, y no una nueva oportunidad de lucro en beneficio de los grandes empresarios.

\footnotetext{
${ }^{1}$ Artículo 2 o del Título I de la Ley Orgánica de la Corporación de Mejoramiento Urbano. (CORMU).

${ }^{2}$ Ver Anexo.
} 
La información juega un rol decisivo en esta tarea. Es necesario publicar y difundir boletines semanales dando cuenta de los avances y de las dificultades. Destacando los casos meritorios y llamando la atención a los rezagados. Convocando a la sana emulación entre los barrios. Otorgando premios a las soluciones mas interesantes. Deben filmarse las obras a fin de socializar por los medios locales los aciertos y los errores. No esconder nada, ya que la desinformación propicia el surgimiento de los rumores malintencionados.

Igualmente decisiva es la participación de los ciudadanos. La organización vecinal debe formar parte de la Junta Directiva de SEVIUTOC, a fin de hacer escuchar su voz en todas sus decisiones.

Salvo casos excepcionales, los damnificados deben cancelar una suma modesta por la ejecución de los proyectos. Es un mínimo reconocimiento a su dignidad, y también a su derecho de exigir por el cumplimiento del servicio que están contratando. También deben participar en la fiscalización de las obras, dejando constancia en el libro de obras de las observaciones que les parezcan pertinentes.

Estimada Michelle:

Estoy seguro que este camino es posible. A pesar de la atmósfera competitiva y mercantil que predomina en nuestra sociedad, es posible articular un esfuerzo colectivo configurando una auténtica cruzada solidaria, con el sector público a la cabeza. Convoquemos a los sindicatos, a organizaciones estudiantiles y femeninas, a las iglesias, a las ONG, a los partidos políticos, a organismos internacionales, a los chilenos en el exilio, en fin, confiemos en los valores y sentimientos ciudadanos. Recuperemos la mística que nos permitió ayer alcanzar cimas inaccesibles, derrotando el escepticismo o la burocracia. Son muchos los chilenos que han dado reiteradas muestras de conservar ideales solidarios. Sólo es necesario saber gatillar tales anhelos, y el terremoto es una oportunidad inmejorable en este sentido.

Creo que esta vía permitirá recuperar la fe en el sector público, tan injustamente desprestigiado por el Transantiago, dado que esta es una iniciativa bajo el control de banqueros y empresarios privados, los así llamados operadores.

Los tocopillanos son de una estirpe análoga a los porteños o los chilotes. Para ellos, no hay en la tierra ciudad más hermosa. Este asentamiento árido y duro, que floreció con el auge salitrero a fines del siglo XIX, genera una increíble identidad con sus habitantes. Compartí el exilio con un buen lote de tocopillanos, y pude constatar el drama que representaba para ellos el desarraigo, la nostalgia con que evocaban sus calles, la plaza Condell, los mariscos, los abruptos cerros cayendo a pico sobre el mar, o las puestas de sol.

Son orgullosos de su tierra estos compatriotas, y sabrán comprometerse con el renacimiento de Tocopilla, si les abrimos un camino para su participación. Tengo la certeza, estimada Michelle, que navegaremos exitosamente por las aguas de la reconstrucción, con el sector público empuñando el timón, y con la compañía solidaria de todos nosotros.

La saluda con afecto,

Miguel Lawner, arquitecto, ex presidente de VICORMU y de CORMUVAL. (19701973).

Santiago, 26 de Noviembre de 2007. 


\section{Anexo 1.: Funcionamiento de las Sociedades Mixtas durantes los Gobiernos de Salvador Allende y Frei Montalva}

\section{Introducción}

Las sociedades mixtas de CORMU con municipios asumieron una diversidad de tareas en materias de desarrollo urbano, durante las administraciones de los presidentes Allende y Frei Montalva.

Se trata de sociedades colectivas civiles de responsabilidad limitada, que se rigen por las cláusulas respectivas que los socios acuerden en el pacto social. El objetivo de las sociedades es amplio, en general se trata de ejecutar proyectos de desarrollo urbano, equipamiento y mejoramiento urbano.

El capital es aportado por ambos socios. El aporte puede ser en dinero, terreno, proyectos en obras que sean previamente valorizadas. Todo esto de común acuerdo entre las corporaciones socias.

La responsabilidad de los socios, por la índole de la sociedad queda limitada al monto de sus respectivos aportes. Las utilidades se reparten entre las corporaciones socios en proporción al capital aportado.

La administración de estas sociedades está a cargo de una junta de administración, compuesta por 3 miembros designados por CORMU, y 3 designados por la corporación socia, sin perjuicio de permitir la presencia de otras personas, en representación por ejemplo de las organizaciones vecinales.

La junta de administración se rige por las cláusulas de la escritura social, y la ejecución de obras, en general, se realiza por propuesta pública.

\section{-Sociedad Mixta Remodelación Manzana Catedral}

En CONCEPCION, la Sociedad Mixta con ese municipio tuvo la conducción del arquitecto Osvaldo Cáceres, y ejecutó el emblemático proyecto de un edificio destinado a oficinas y comercio, en la remodelación de la manzana adyacente a la Catedral. El proyecto estuvo a cargo del arquitecto Roberto Goycolea.

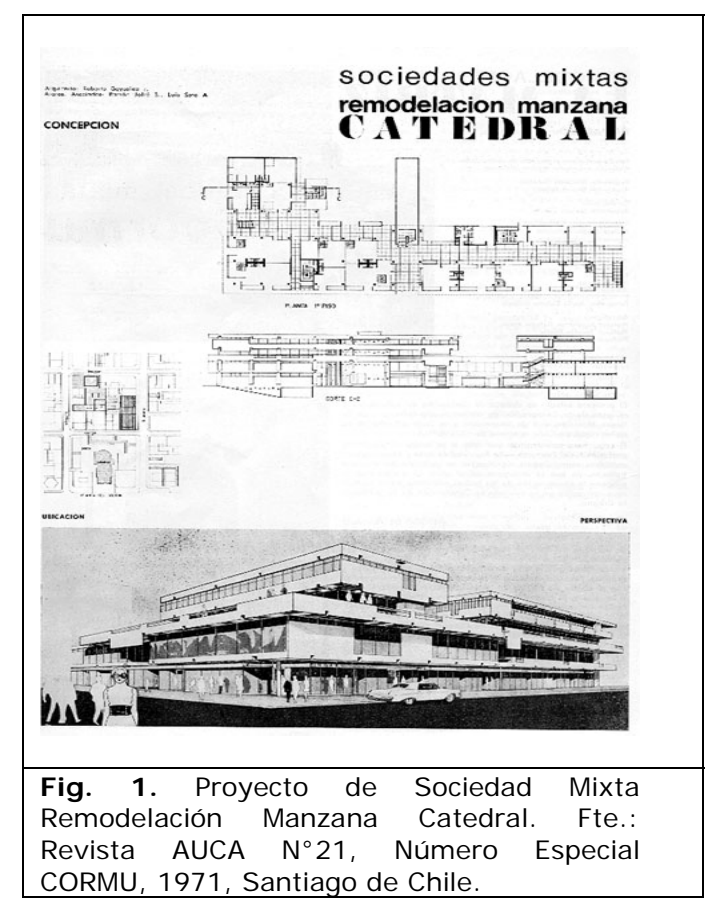




\section{URCOREI, sociedad mixta con la I. Municipalidad de La Reina}

Esta sociedad mixta con la Municipalidad de La Reina, asumió un gran proyecto de viviendas de autoconstrucción, para sus funcionarios en la Villa La Reina. Iniciativa impulsada por los alcaldes de entonces, arquitectos Fernando Castillo Velasco y Eduardo San Martín. Este proyecto fue reactivado por la misma sociedad en los años 2000, con apoyo de la Junta de Andalucía (España).

\section{QUICORMU, sociedad mixta con la Municipalidad de I quique}

Fue presidida por el arquitecto Jorge Wong y que llevó a cabo la construcción de las cabañas Primeras Piedras, levantadas con la finalidad de acoger a los participantes al Campeonato Mundial de Pesca Submarina que tuvo lugar en 1972 en Iquique. También en esta ciudad, IQUICORMU se encargó de proyectar y construir la primera etapa del Balneario Playa Cavancha, que dio pie a la recuperación del borde costero que Iquique disfruta actualmente.

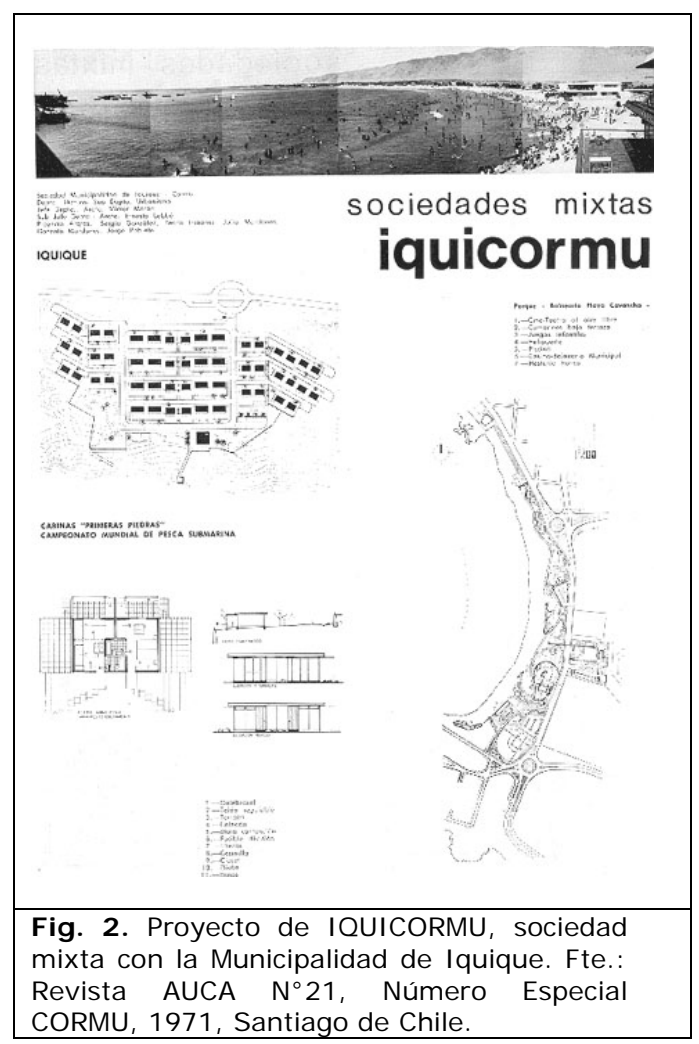

CORMUVAL, sociedad mixta con la I. Municipalidad de Valparaíso Entidad dirigida por el delegado de CORMU en la región, arquitecto Esteban Rodríguez Soto.

Un proyecto de gran acogida popular, fue la renovación de los ascensores del puerto que presentaban instalaciones muy precarias.

El proyecto mas relevante de esta sociedad fue la primera restauración de la Iglesia La Matriz, que mostraba asentamientos estructurales de cierto riesgo. El proyecto estuvo a cargo de la arquitecta e historiadora Myriam Waisberg, y procuró devolverle al templo los atributos arquitectónicos que lucía hacia 1842, año de su terminación. 


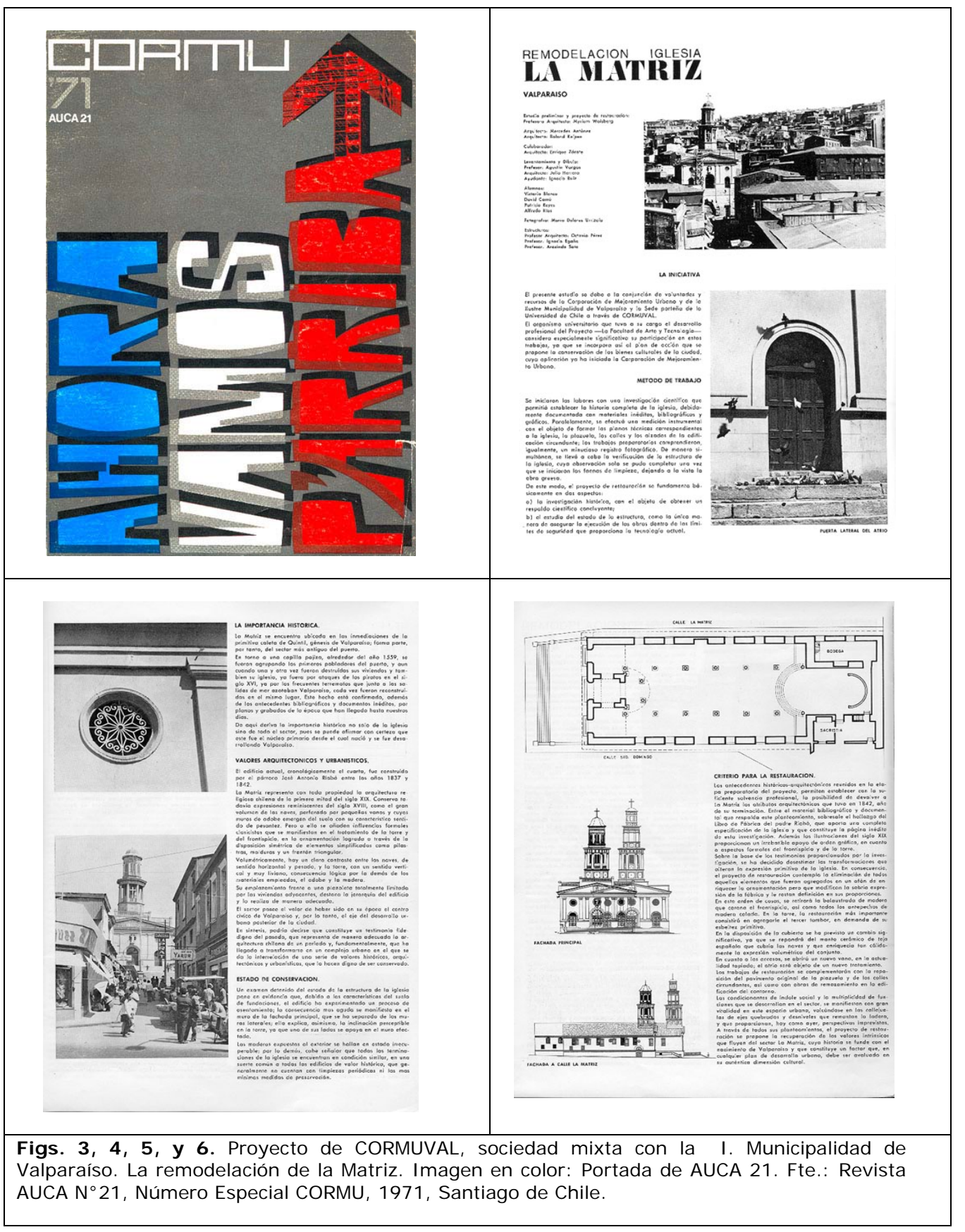

VI CORMU, sociedad mixta con la I. Municipalidad de Viña del Mar

Entre otras iniciativas, adquirió el Palacio Rioja que se encontraba abandonado, y lo adecuó a su funcionamiento como centro cultural, función que conserva hasta nuestros días. El arquitecto Julián Larraín, de destacada presencia en la zona, ejerció las funciones de gerente ejecutivo.

El proyecto más significativa de la VICORMU, fue la remodelación del Portal Álamos, importante galería comercial de dos pisos, situada en plena calle Valparaíso, con un amplio frente a dicha vía, y que sufrió un incendio de grandes proporciones dejando en la calle a un gran número de pequeños comerciantes. 


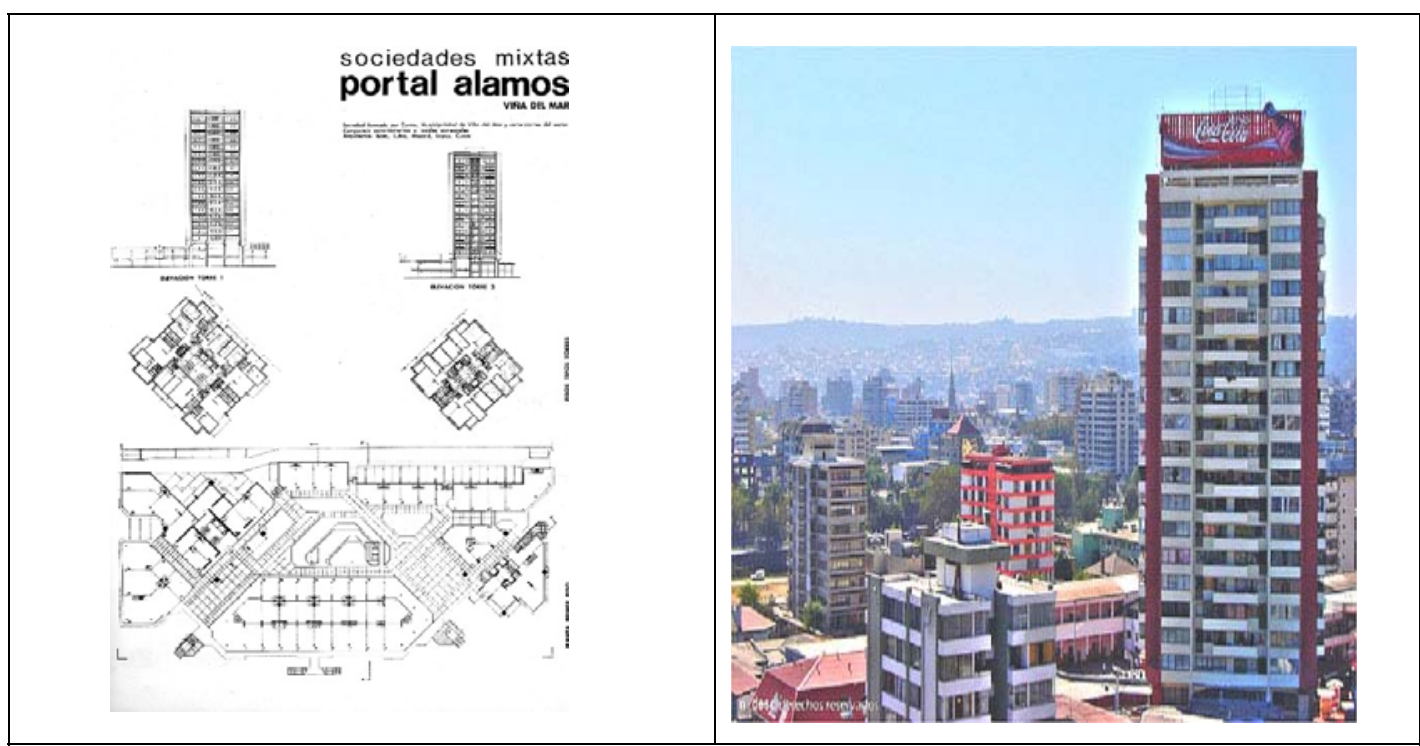

Figs. 7 y 8. Proyecto de VICORMU, sociedad mixta con la I. Municipalidad de Viña del Mar. Portal Álamos. Fte.: Revista AUCA N²1, Número Especial CORMU, 1971, Santiago de Chile.

Un breve estudio de factibilidad demostró que no tenía sentido intentar reconstruir el sector afectado, en primer lugar por su escaso valor patrimonial, y además, debido a los serios riesgos de nuevos siniestros, como consecuencia de las numerosas intervenciones no autorizadas en las instalaciones de gas y electricidad. Por otra parte, el alto valor comercial del sector adquirido con el curso de los años, aconsejaban la realización de un proyecto en altura con evidente beneficios de rentabilidad.

La VICORMU adquirió el predio, y se esforzó por organizar a todos los locatarios cualquiera que fuera su condición, ya sea propietarios o arrendatarios, a fin de integrarlos al proyecto desde un comienzo. Los arrendatarios respondieron positivamente, no así los propietarios que se manifestaron escépticos y depositaban su confianza en las indemnizaciones de las compañías de seguro, que - por lo demás- solo un mínimo de ellos había contraído.

Cuando aparecimos con la maqueta del proyecto consistente en una placa comercial en dos niveles, y dos torres de vivienda de 15 pisos, las cosas cambiaron, mas aún cuando dimos a conocer las condiciones financieras del proyecto, otorgando facilidades especiales a todos los locatarios del conjunto. Los propietarios intentaron una última acción tratando de desplazar a los arrendatarios, argumentando que carecían de derechos para optar al proyecto, pero la verdad es que había lugar para todos.

Al final ganamos todos: propietarios y arrendatarios que adquirieron un espléndido local comercial en el sector mas codiciado de esos años. y la VICORMU, porque los proyectos de vivienda permitieron recuperar con creces la inversión inicial.

He querido extenderme en este ejemplo, porque señala un camino de reconstrucción en favor de los damnificados, a diferencia de lo ocurrido con la tragedia de calle Serrano en Valparaíso, donde no hubo esfuerzo alguno por organizar a los afectados, y formular un proyecto accesible a sus recursos. En calle Serrano, la reconstrucción prescinde de los modestos locatarios afectados por la explosión, que serán sustituidos por sectores sociales con capacidad de pago a nivel de la renovación programada. 


\section{Anexo 2. Algunas de las réplicas a la carta del Arqto. M. Lawner Del Arqto. Fernando Castillo Velasco}

Certifica el Arqto. Castillo Velasco en su réplica que en La Reina aún existe la URCOREI, sociedad que él organizó entre la Municipalidad y el Ministerio de Vivienda con la cual hicieron el Parque Industrial; el parque La Quintrala; la Villa La Reina; en los años 1960. En el último período del Arqto. Castillo Velasco, realizaron los edificios para los funcionarios municipales; la remodelación de los pasajes de Villa La Reina; las casas en de patios traseros de las casas de los padres; los torreones de La Reina etc. Lo refiere para certificar lo exitosa que resulta la asociación que está proponiendo el Arqto. Lawner en su carta a la Presidenta.

\section{Del Arqto. Víctor Gubbins}

Comparte plenamente la recomendación de volver a utilizar el mecanismo exitoso que tuvo la asociación entre la CORMU y las Municipalidades del país, vinculando en esta ocasión al SERVIU con las Municipalidades para aterrizar el plan habitacional en la realidad de nuestras ciudades. Más aún, refiere el Arqto. Gubbins que lo ha propuesto en numerosas oportunidades, incluso en el propio MINVU, agregando que el SERVIU de Santiago debiera subdividirse al menos en cuatro o cinco unidades independientes (norte, sur, oriente, poniente, centro) que constituyan en la Región Metropolitana sociedades con las diferentes Municipalidades para darle una solución definitiva al tema habitacional. Y -agrega- que no solamente en lo que se refiere a construcción de conjuntos, reconstrucción, en este caso, sino que también para crear grupos de apoyo de asistencia técnica a quienes aún emplean la autoconstrcucción - y que son muchos - a lo largo del país, de manera que construyan mejor y puedan accedeer con subsidio a la tramitación municipal. Agrega que en los terremotos se aprecia que gran parte de las viviendas colapsan por mala construcción o mal uso de los materiales percibiendo inmediatamente que no hay técnicos involucrados, ni menos la Municipalidad. Señala que si esa asistencia fuera masiva, no habríqa necesidad de la "ley del mono", la cual sólo sirve para que todos amplíen sus casas sin permiso porque se sabe que cada dos años se les perdona, pero después sufren cuando se les caen o deterioran. Desea, finalmente, que la Presidenta escuche al Arqto. Lawner.

\section{De la Arqta. Ximena de la Barra}

Ofrece su colaboración, señalando que el punto clave es el del imprescindible rol de Estado (mas allá del facilismo de los subsidios) y la falacia de las soluciones individuales. Señala que no sólo no se construye sino que además se enciende la mecha para la próxima tragedia. Cita su propia experiencia en Turquía, Nicaragua, El Salvador, entre otros países, observando que la autoayuda individual sólo da técnicas de construcción que matan al próximo terremoto.

\section{Del Director de Obras de Puerto Montt, D. Nelson González.}

Participa de la propuesta renovadora, la que permite incluir a la sociedad en la solución de las crisis, sobre todo cuando se trata de corregir los errores humanos que las provocan. Refiere que junto al Presidente de la Asociación Chilena de Municipalidades, alcalde de Puerto Montt, Rabindranath Quinteros Lara y a otros profesionales de varios Municipios de Santiago se pusieron a disposición de las autoridades para trabajar en los momentos inmediatos del terremoto. EI SERVIU les asignó las Poblaciones Padre Hurtado y Los Andes. Las edificaciones fallaron por estar emplazadas en terrenos de rellenos, aluviones en el pie del cerro que corona la ciudad, y un diseño con una estructura unitaria que transforma las viviendas en un tren unidss por las vigas de primer piso y las enfierraduras de losas. Al fallar el terreno de fundación en el área de relleno de fundaciones y radieres por desplazamientos del terreno de fundación, las fallas estructurales se pasaron de una vivienda a la otra, generando fallas en prácticamente todas las manzanas. Señala que el detalle de lo expuesto, por supuesto, es más complejo, pero no le 
cabe ninguna duda que si la reconstrucción se hace en los mismos terrenos habrá que tomar precauciones especiales con respecto a los terrenos. Mirando desde la costanera hacia la Población Padre Hurtado su observación encontraba mayor asidero. Refiere, en conclusión, que se comprometieron a desarrollar los nuevos proyectos de las dos poblaciones. Reitera la necesidad de una institucionalidad que coordine los distintos servicios definiendo las áreas que a cada uno les corresponderá aportar a las soluciones que requiere la ciudad. Teniendo la certeza que los errores sólo se pueden perdonar una sólo vez cuando se trata de seres humanos involucrados y que cargan con las más básicas carencias, concluye, imbuido de la gran capacidad solidaria del Arqto. Lawner, deseando que la carta sea escuchada.

\section{De la Arqta. Teresa Segura, desde Bilbao.}

Teresa Segura, arquitecta radicada en Bilbao, España, junto con su esposo Esteban Rodríguez Soto, su hijo Diego, y su nuera Ema, todos arquitectos, ofrecen su colaboración a la reconstrucción de Tocopilla, participando de las ideas del Arqto. Lawner, aunque no saben como canalizar este deseo. 